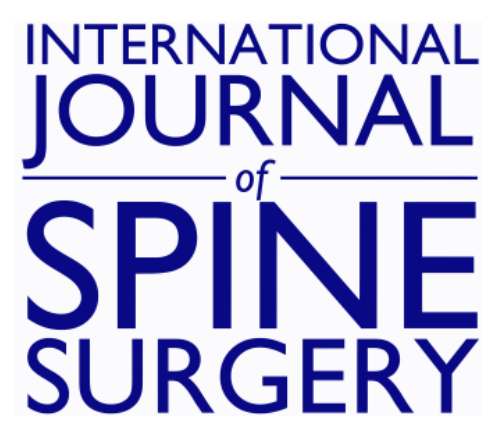

\title{
Differences in Clinically Important Physical Function Improvement in Workers' Compensation Population
}

Elliot D.K. Cha, Conor P. Lynch, Caroline N. Jadczak, Shruthi Mohan, Cara E. Geoghegan and Kern Singh

Int J Spine Surg published online 17 February 2022

http://ijssurgery.com/content/early/2022/03/01/8186

This information is current as of April 26, 2023.

Email Alerts Receive free email-alerts when new articles cite this article. Sign up at:

http://ijssurgery.com/alerts

The International Journal of Spine Surgery

2397 Waterbury Circle, Suite 1,

Aurora, IL 60504, Phone: +1-630-375-1432 


\title{
Differences in Clinically Important Physical Function Improvement in Workers' Compensation Population
}

\author{
ELLIOT D.K. CHA, MS ${ }^{1}$; CONOR P. LYNCH, MS ${ }^{1}$; CAROLINE N. JADCZAK, BS ${ }^{1}$; SHRUTHI MOHAN, BS ${ }^{1}$; \\ CARA E. GEOGHEGAN, BS ${ }^{1}$; AND KERN SINGH, MD ${ }^{1}$ \\ ${ }^{I}$ Department of Orthopaedic Surgery, Rush University Medical Center, Chicago, IL, USA
}

\begin{abstract}
Background: Patients receiving workers' compensation demonstrate a propensity for poorer postoperative outcomes. This study aims to determine rates of minimum clinically important difference (MCID) achievement in patients receiving workers' compensation following transforaminal lumbar interbody fusion (TLIF).

Methods: We retrospectively reviewed a prospective surgical database from 2015 to 2020 for primary, single-level TLIFs with posterior instrumentation for degenerative spinal pathologies. Visual analog scale (VAS) for back and leg, Oswestry Disability Index (ODI), 12-Item Short Form Physical Component Summary (SF-12 PCS), and Patient-Reported Outcome Measurement Information System physical function (PROMIS-PF) were collected pre- and postoperatively. Patients were separated by workers' compensation (WC) status. Propensity score matching was performed to account for differences in demographic characteristics. Postoperative improvements in patient-reported outcome measures (PROMs) were calculated using paired Student's $t$ test, and intergroup differences were determined by Mann-Whitney $U$ test. Achievement of MCID was determined using established values, and intergroup differences were assessed using $\chi^{2}$ analysis.

Results: A total of 121 patients were included in this study with $29 \mathrm{WC}$ and 92 non-WC patients. The mean age was 53.5 years with the majority being men $(63.6 \%)$ and nonobese $(54.5 \%)$. WC patients demonstrated significantly poorer PROM values at all timepoints except for preoperative VAS back $(P=0.297)$ and leg $(P=0.475)$. Overall achievement of MCID was significantly lower for WC patients for VAS back $(P=0.040)$, ODI $(P=0.001)$, SF-12 PCS $(P=0.010)$, and PROMIS-PF $(P$ $=0.039$ ).

Conclusion: WC patients demonstrated poorer postoperative outcomes at multiple timepoints. Additionally, a significantly lower rate of MCID achievement for back pain, disability, and physical function was observed for WC patients.

Clinical Relevance: These results suggest that WC patients may require alternative preoperative counseling about realistic expectations for improvement following lumbar fusion.
\end{abstract}

Level of Evidence: 3.

Minimally Invasive Surgery

Keywords: workers' compensation, lumbar fusion, propensity score match, patient-reported outcome measures (PROMs)

\section{INTRODUCTION}

Lower back pain is among the top causes of years lived with a disability among developed nations, ${ }^{1}$ and among the working population, it is believed to be one of the most reported symptoms of injuries. ${ }^{2}$ Not only have injuries of this type placed an increased financial burden on employers, ${ }^{2}$ but also on patients where over 100 million workdays have been reportedly lost within a given year. ${ }^{3}$ With the high prevalence of back injuries, there are an estimated $43 \%$ of patients who go on to receive surgical interventions, ${ }^{4}$ which places increased importance on the extent of postoperative improvement that such procedures as a transforaminal lumbar interbody fusion (TLIF) can provide to this specific population.

Receiving workers' compensation (WC) has typically been associated with poorer surgical outcomes and dissatisfaction, ${ }^{5}$ with lumbar fusion patients experiencing increased rates of complications, delayed return to work, and even higher rates of permanent disability. ${ }^{6}$ Past studies have suggested that differences in postoperative outcomes among the WC population may be attributed to differences in underlying clinical factors, such as severity of underlying pathology and the presence of significant comorbid conditions. ${ }^{7-9}$ Other studies have also suggested there may be other baseline characteristics that place WC patients at risk for poorer outcomes, such as socioeconomic factors and preoperative expectations. ${ }^{10-12}$ In addition to potential risks for poorer surgical outcomes, a number of studies have also reported negative effects of WC status on improvement of postoperative pain and disability, as measured by the visual analog scale (VAS) and Oswestry Disability Index (ODI). ${ }^{13-15}$ Moreover, persistent pain among 
this patient population has also led to the observation that WC patients are at risk for increased postoperative opioid use, additional costs to the healthcare system, and potential for worse outcomes. ${ }^{16-18}$ While evaluation of operative outcomes and patient-reported outcome measures (PROMs) has provided the means to elucidate the potential negative effects of WC status, clinicians have begun to focus on a more patient-centered evaluation of postoperative recovery.

Efforts to assess postoperative outcomes in a patientcentered manner have resulted in the emergence of such metrics as the minimum clinically important difference (MCID), which takes into account an individual's selfassessment of their health to determine an improved or unimproved state. This self-assessment is especially important among WC patients, as past studies have demonstrated this population is more likely to rate their health as poor. ${ }^{19}$ Additionally, studies by both Hijji et $\mathrm{al}^{20}$ and Djurasovic et $\mathrm{al}^{21}$ were able to suggest that WC status may be a potential risk factor for failure to achieve an MCID for back pain (VAS back) and physical function, as evaluated by 36-Item Short Form physical component score. While both studies may provide an added reason for clinicians to appropriately counsel WC patients on their postoperative recovery, there remains a need for a more comprehensive investigation. Therefore, this study aims to determine the impact of WC status on the achievement of an MCID for pain, disability, and physical function following minimally invasive (MIS) TLIF. Our hypothesis is that WC will similarly be associated with a lower rate of MCID achievement for pain, disability, and physical function by the 1-year timepoint.

\section{METHODS}

\section{Patient Population}

Prior to the initiation of the study, Institutional Review Board approval (ORA 14051301) and subsequently written patient informed consent were obtained. Patients logged in a prospectively maintained surgical database were retrospectively reviewed to identify eligible individuals who underwent a lumbar fusion between January 2015 and February 2020. Inclusion criteria were set as primary, elective, single-level MIS TLIF procedures. Patients were excluded for undergoing procedures for traumatic, infectious, or malignant etiologies as well as failing to complete a preoperative PROM or missing insurance information. All procedures were performed either in an outpatient hospital center or an ambulatory surgical center by a single surgeon at a single institution.

\section{Data Collection}

All patients had their demographic and perioperative information collected for the purposes of this study. Demographic information was restricted to age, gender,

Table 1. Unmatched patient baseline demographics.

\begin{tabular}{|c|c|c|c|c|}
\hline Characteristic & Total $(n=634)$ & Non-WC $(n=374)$ & $\mathrm{WC}(n=260)$ & $P$ Value $^{\mathrm{a}}$ \\
\hline Age, mean $\pm S D$ & $50.8 \pm 11.7$ & $53.9 \pm 11.7$ & $46.4 \pm 10.0$ & $<0.001$ \\
\hline Gender & & & & $<0.001$ \\
\hline Female & $37.9 \%(240)$ & $48.7 \%(182)$ & $22.3 \%(58)$ & \\
\hline Male & $62.1 \%(394)$ & $51.3 \%(192)$ & $77.7 \%(202)$ & \\
\hline Ethnicity & & & & $<0.001$ \\
\hline White & $66.3 \%(420)$ & $79.4 \%(297)$ & $47.5 \%(123)$ & \\
\hline Nonwhite & $33.7 \%(213)$ & $20.6 \%(77)$ & $52.5 \%(136)$ & \\
\hline Body mass index & & & & 0.003 \\
\hline$<30 \mathrm{~kg} / \mathrm{m}^{2}$ & $51.9 \%(328)$ & $56.8 \%(212)$ & $44.8 \%(116)$ & \\
\hline$\geq 30 \mathrm{~kg} / \mathrm{m}^{2}$ & $48.1 \%(304)$ & $43.1 \%(161)$ & $55.2 \%(143)$ & \\
\hline Smoking status & & & & $<0.001$ \\
\hline Nonsmoker & $80.8 \%(512)$ & $86.1 \%(322)$ & $73.0 \%(190)$ & \\
\hline Smoker & $19.2 \%(122)$ & $13.9 \%(52)$ & $26.9 \%(70)$ & \\
\hline Diabetic status & & & & 0.976 \\
\hline Nondiabetic & $88.8 \%(563)$ & $88.8 \%(332)$ & $88.9 \%(44)$ & \\
\hline Diabetic & $11.2 \%(71)$ & $11.2 \%(42)$ & $11.1 \%(4)$ & \\
\hline $\begin{array}{l}\text { American Society of Anesthesiologists } \\
\text { Score }\end{array}$ & & & & 0.742 \\
\hline$<2$ & $82.8 \%(521)$ & $83.2 \%(308)$ & $82.2 \%(213)$ & \\
\hline$\geq 2$ & $17.2 \%(108)$ & $16.7 \%(62)$ & $17.8 \%(46)$ & \\
\hline Charlson Comorbidity Index Score & & & & 0.001 \\
\hline$\leq 1$ & $24.9 \%(154)$ & $19.9 \%(73)$ & $32.1 \%(81)$ & \\
\hline$>1$ & $75.1 \%(464)$ & $80.1 \%(293)$ & $67.9 \%(171)$ & \\
\hline
\end{tabular}

Abbreviation: WC, workers' compensation.

Data presented as \% (n) unless otherwise indicated. Boldface indicates statistical significance.

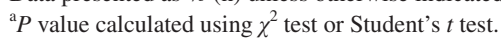


Table 2. Matched patient baseline demographics.

\begin{tabular}{|c|c|c|c|c|}
\hline Characteristic & Total $(n=121)$ & Non-WC $(n=92)$ & WC $(n=29)$ & $P$ Value $^{\mathrm{a}}$ \\
\hline Age, mean $\pm \mathrm{SD}$ & $53.5 \pm 9.4$ & $54.6 \pm 9.7$ & $50.0 \pm 7.4$ & 0.023 \\
\hline$<50 \mathrm{y}$ & $34.7 \%(42)$ & $31.5 \%(29)$ & $44.8 \%(13)$ & \\
\hline $50-64$ y & $62.0 \%(75)$ & $64.1 \%(59)$ & $55.2 \%(16)$ & \\
\hline$>65 y$ & $3.3 \%(4)$ & $4.3 \%(4)$ & $0.0 \%(0)$ & \\
\hline Gender & & & & 0.044 \\
\hline Female & $36.4 \%(44)$ & $41.3 \%(38)$ & $20.7 \%(6)$ & \\
\hline Male & $63.6 \%(77)$ & $58.7 \%(54)$ & $79.3 \%(23)$ & \\
\hline Ethnicity & & & & $<0.001$ \\
\hline White & $78.5 \%(95)$ & $87.0 \%(80)$ & $51.7 \%(15)$ & \\
\hline Nonwhite & $21.5 \%(26)$ & $13.0 \%(12)$ & $48.3 \%(14)$ & \\
\hline Body mass index & & & & 0.437 \\
\hline$<30 \mathrm{~kg} / \mathrm{m}^{2}$ & $54.5 \%(66)$ & $56.5 \%(52)$ & $48.3 \%(14)$ & \\
\hline$\geq 30 \mathrm{~kg} / \mathrm{m}^{2}$ & $44.5 \%(55)$ & $43.5 \%(40)$ & $51.7 \%(15)$ & \\
\hline Smoking status & & & & 0.078 \\
\hline Nonsmoker & $88.4 \%$ (107) & $91.3 \%(84)$ & $79.3 \%(23)$ & \\
\hline Smoker & $11.6 \%(14)$ & $8.7 \%(8)$ & $20.7 \%(6)$ & \\
\hline Diabetic status & & & & 0.423 \\
\hline Nondiabetic & $90.1 \%$ (109) & $91.3 \%(84)$ & $86.2 \%(25)$ & \\
\hline Diabetic & $9.9 \%(12)$ & $8.7 \%(8)$ & $13.8 \%(4)$ & \\
\hline American Society of Anesthesiologists Score & & & & 0.794 \\
\hline$<2$ & $84.3 \%(102)$ & $84.8 \%(80)$ & $82.8 \%(24)$ & \\
\hline$\geq 2$ & $15.7 \%(19)$ & $15.2 \%(14)$ & $17.2 \%(5)$ & \\
\hline Charlson Comorbidity Index Score & & & & 0.331 \\
\hline$\leq 1$ & $23.6 \%(29)$ & $26.1 \%(24)$ & $17.2 \%(32)$ & \\
\hline$>1$ & $76.4 \%(92)$ & $73.9 \%(68)$ & $82.8 \%(12)$ & \\
\hline Duration of symptoms & & & & 0.005 \\
\hline$<6 \mathrm{mo}$ & $20.4 \%(22)$ & $19.5 \%(16)$ & $23.1 \%(6)$ & \\
\hline 6 mo to $1 \mathrm{y}$ & $21.3 \%(23)$ & $14.6 \%(12)$ & $42.3 \%(11)$ & \\
\hline$>1 \mathrm{y}$ & $58.3 \%(63)$ & $65.9 \%(54)$ & $34.6 \%(9)$ & \\
\hline Time to surgery, mo, mean $\pm \mathrm{SD}$, mo (n) & $4.9 \pm 10.4(114)$ & $4.7 \pm 11.4(92)$ & $5.9 \pm 4.1(22)$ & 0.628 \\
\hline
\end{tabular}

Abbreviation: WC, workers' compensation.

Data provided as \% (n) unless otherwise indicated. Boldface indicates statistical significance.

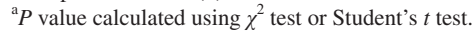

ethnicity, body mass index, and diabetic and smoker status. Additionally, comorbidity burden as measured by the Charlson Comorbidity Index (CCI) and American Society of Anesthesiologists physical classification was recorded. Perioperative information was also recorded, which included mean duration of preoperative symptoms, mean length of time from first clinical visit to surgery, operative duration (skin incision to skin closure), estimated blood loss (EBL), length of postoperative stay, and day of discharge. Underlying spinal pathology associated with the procedure was also recorded.

The primary outcome of interest was PROMs, which were recorded at the preoperative timepoint as well as the 6-week, 12-week, 6-month, and 1-year postoperative follow-up. PROMs evaluated back and leg pain, disability, and physical function using the following metrics: VAS, ODI, 12-Item Short Form physical component score (SF-12 PCS), and Patient-Reported Outcome Measurement Information System physical function (PROMIS-PF).

\section{Statistical Analysis}

Prior to analysis, patients were categorized into two groups according to their insurance collected: WC and non-WC. Due to potential confounding effects of demographics between both groups, a propensity score was calculated to match non-WC to WC patients. More specifically, non-WC patients were matched to the WC cohort based on demographic characteristics, CCI, and American Society of Anesthesiologists scores using the nearest neighbor to generate a match. Unmatched patients were excluded from the study population. Comparison of the unmatched cohort can be found in Table 1, and the matched cohort is summarized in Table 2. Following propensity score matching, the study population was evaluated for differences in demographic and perioperative characteristics using either a $t$ test (continuous) or $\chi^{2}$ test (categorical). All PROMs were evaluated, at all timepoints, for postoperative improvement from baseline values using a paired Student's $t$ test. Differences in PROM values between groups were evaluated using Mann-Whitney $U$ test. To determine the effects of duration of preoperative symptoms, time from first clinical appointment to date of surgery, and WC status, a multiple linear regression was performed. Achievement of MCID was calculated using the following established values in the literature for all PROMs: 1.2 (VAS back), ${ }^{22} 1.6$ (VAS leg), ${ }^{22} 12.8$ (ODI), ${ }^{22} 4.0$ (SF-12 PCS), ${ }^{23}$ and 8.0 (PROMIS-PF). ${ }^{24}$ Impact of WC status on achievement of MCID was evaluated using logistic regression. All statistical tests 
were performed in StataMP 16.1 (StataCorp, College Station, TX), and an $a=0.05$ was set to reject the null hypothesis.

\section{RESULTS}

A total of 634 patients were initially screened as eligible for this study. Following propensity score matching, the final study cohort was 121 individuals, with 92 categorized as non-WC and 29 as WC. The final study cohort had an average age of 53.5 years with the majority of patients aged between 50 and 64 years regardless of insurance status $(64.1 \%$ vs $55.2 \%$ ). Additionally, a higher proportion of the study cohort were Caucasian ethnicity $(78.5 \%)$ and male $(63.6 \%)$. The unmatched cohort demonstrated significant differences in terms of age, gender, ethnicity, body mass index, smoker status, and CCI value (all $P \leq 0.003$; Table 1). Following propensity score matching, only age, gender, and ethnicity differed between groups (all $P \leq 0.05$ ) (Table 2). A larger proportion of non-WC patients reported a duration of preoperative symptoms $>1$ year compared to the WC cohort $(P \leq 0.005)$. Mean time from initial clinical visit to date of surgery was 4.9 months and did not significantly differ between WC and non-WC groups $(P=0.628)$ (Table 2). Majority of patients suffered from degenerative spondylolisthesis $(65.4 \%)$ and had a mean operative length of $124.5 \pm 23.5$ minutes, an average blood loss of $48.5 \pm 25.2 \mathrm{~mL}$, and stayed postoperatively for an average of 29.2 hours. Perioperative characteristics also demonstrated no significant differences except for a higher proportion of non-WC patients $(28.6 \%$ vs $8.7 \%)$ having an underlying spinal pathology of isthmic spondylolisthesis $(P=0.049)$ (Table 3).

\section{VAS Back and Leg}

Non-WC patients demonstrated significant improvements in VAS back from the baseline values at the 6-week, 12-week, 6-month, and 1-year timepoint (all $P<0.001$ ). VAS leg also significantly improved from preoperative scores at 6 weeks through 1 year follow-up (all $P<0.001$ ). WC patients only demonstrated significant improvements from baseline levels at 6 weeks, 12 weeks, and 6 months (all $P<0.01$ ). VAS leg improved from baseline scores at 12 weeks and 6 months only (all $P<0.05$ ). Direct comparison of VAS back values demonstrated significantly higher values for the WC group at all postoperative timepoints (all $P<0.01$ ), but not at the preoperative timepoint $(P=0.297)$. Similarly, comparative analysis of VAS leg values between groups demonstrated significant differences between groups at all postoperative timepoints (all $P<0.05)$ but also not at the preoperative timepoint $(P=$ 0.475). A summary of results can be found in Table 4 . When accounting for duration of preoperative symptoms, WC status was not a significant effector of mean VAS back and VAS leg at the preoperative. However, postoperatively WC status largely remained a significant predictor of mean pain scores even when accounting for duration of preoperative symptoms and time from initial clinical visit to date of surgery (Table 5).

\section{ODI}

Non-WC patients demonstrated significant improvements in ODI from baseline values from 6 weeks to 1 year (all $P<0.001$ ). Comparatively, WC patients did not demonstrate significant improvements in ODI from baseline levels at any postoperative timepoints (all $P>0.05$ ). Direct comparison of ODI between groups demonstrated significantly worse values for WC patients at all timepoints (all $P<0.01$ ) including the preoperative timepoint $(P=0.003)$. A summary of results can be found in Table 4 .

Table 3. Perioperative characteristics.

\begin{tabular}{|c|c|c|c|c|}
\hline Characteristic & Total $(n=121)$ & Non-WC $(n=92)$ & WC $(n=29)$ & $P$ Value $^{\mathrm{a}}$ \\
\hline \multicolumn{5}{|l|}{ Spinal pathology } \\
\hline Degenerative disc disease & $55.3 \%(67)$ & $53.3 \%(49)$ & $62.1 \%(18)$ & 0.405 \\
\hline Degenerative spondylolisthesis & $65.4 \%(70)$ & $61.9 \%(52)$ & $78.3 \%(18)$ & 0.144 \\
\hline Isthmic spondylolisthesis & $24.3 \%(26)$ & $28.6 \%(24)$ & $8.7 \%(2)$ & 0.049 \\
\hline Operative time, min, mean \pm SD & $124.5 \pm 23.5$ & $123.9 \pm 23.2$ & $126.1 \pm 24.9$ & 0.663 \\
\hline Estimated blood loss, $\mathrm{mL}$, mean $\pm \mathrm{SD}, \mathrm{mL}$ & $48.5 \pm 25.2$ & $48.5 \pm 24.3$ & $48.3 \pm 28.3$ & 0.962 \\
\hline Length of stay, $h$, mean \pm SD & $29.2 \pm 18.7$ & $29.4 \pm 19.7$ & $28.8 \pm 15.4$ & 0.877 \\
\hline Day of discharge & & & & 0.310 \\
\hline POD 0 & $19.0 \%(23)$ & $18.5 \%(17)$ & $20.7 \%(6)$ & \\
\hline POD 1 & $61.2 \%(74)$ & $63.0 \%(58)$ & $55.1 \%(16)$ & \\
\hline POD 2 & $15.7 \%(19)$ & $13.0 \%(12)$ & $24.1 \%(7)$ & \\
\hline POD 3 & $4.1 \%(5)$ & $5.5 \%(5)$ & $0.0 \%(0)$ & \\
\hline
\end{tabular}

Abbreviations: POD, postoperative day; WC, workers' compensation.

Data provided as \% (n) unless otherwise indicated. Boldface indicates statistical significance.

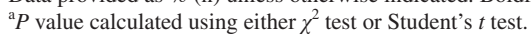


Table 4. Postoperative improvement of outcomes between groups.

\begin{tabular}{|c|c|c|c|c|c|}
\hline $\begin{array}{c}\text { Patient-Reported } \\
\text { Outcome Measures }\end{array}$ & Non-WC, Mean \pm SD $(n)$ & $P$ Value $^{\mathrm{a}}$ & WC, Mean \pm SD $(n)$ & $P$ Value $^{\mathrm{a}}$ & $P$ Value $^{\mathrm{b}}$ \\
\hline \multicolumn{6}{|l|}{ VAS back } \\
\hline Preoperative & $6.0 \pm 2.6(92)$ & - & $6.7 \pm 2.2(29)$ & - & 0.297 \\
\hline $6 \mathrm{wk}$ & $3.3 \pm 2.6(83)$ & $<0.001$ & $5.1 \pm 2.0(25)$ & 0.001 & 0.001 \\
\hline $12 \mathrm{wk}$ & $2.6 \pm 2.2(76)$ & $<0.001$ & $5.3 \pm 2.5(24)$ & 0.004 & $<0.001$ \\
\hline $6 \mathrm{mo}$ & $2.5 \pm 2.4(75)$ & $<0.001$ & $5.3 \pm 2.5(25)$ & 0.007 & $<0.001$ \\
\hline $1 \mathrm{y}$ & $2.2 \pm 2.4(48)$ & $<0.001$ & $4.7 \pm 2.7(13)$ & 0.147 & 0.004 \\
\hline \multicolumn{6}{|l|}{ VAS leg } \\
\hline Preoperative & $5.3 \pm 3.0(92)$ & - & $5.0 \pm 3.0(29)$ & - & 0.475 \\
\hline $6 \mathrm{wk}$ & $2.5 \pm 2.5(83)$ & $<0.001$ & $4.1 \pm 2.7(25)$ & 0.188 & 0.012 \\
\hline $12 \mathrm{wk}$ & $1.9 \pm 2.4(77)$ & $<0.001$ & $3.6 \pm 2.7(24)$ & 0.032 & 0.004 \\
\hline $6 \mathrm{mo}$ & $1.6 \pm 2.5(75)$ & $<0.001$ & $3.4 \pm 2.5(25)$ & 0.044 & $<0.001$ \\
\hline $1 \mathrm{y}$ & $1.9 \pm 2.9(48)$ & $<0.001$ & $4.1 \pm 2.7(13)$ & 0.223 & 0.002 \\
\hline \multicolumn{6}{|l|}{ ODI } \\
\hline Preoperative & $35.8 \pm 13.9(92)$ & - & $45.1 \pm 15.6(29)$ & - & 0.003 \\
\hline $6 \mathrm{wk}$ & $28.5 \pm 18.1(84)$ & $<0.001$ & $46.6 \pm 17.3(25)$ & 0.696 & $<0.001$ \\
\hline $12 \mathrm{wk}$ & $22.4 \pm 15.8(78)$ & $<0.001$ & $43.5 \pm 14.3(24)$ & 0.439 & $<0.001$ \\
\hline $6 \mathrm{mo}$ & $15.7 \pm 13.6(76)$ & $<0.001$ & $39.1 \pm 18.9(25)$ & 0.088 & $<0.001$ \\
\hline $1 \mathrm{y}$ & $15.7 \pm 18.7(48)$ & $<0.001$ & $30.3 \pm 21.3(13)$ & 0.071 & 0.009 \\
\hline \multicolumn{6}{|l|}{ SF-12 PCSy } \\
\hline Preoperative & $32.4 \pm 8.0(88)$ & - & $27.4 \pm 6.6(27)$ & - & 0.001 \\
\hline $6 \mathrm{wk}$ & $34.0 \pm 9.2(77)$ & 0.138 & $26.3 \pm 6.0(22)$ & 0.319 & 0.001 \\
\hline $12 \mathrm{wk}$ & $38.1 \pm 10.6(68)$ & 0.001 & $27.5 \pm 5.7(23)$ & 0.775 & $<0.001$ \\
\hline $6 \mathrm{mo}$ & $42.9 \pm 11.0(62)$ & $<0.001$ & $28.3 \pm 7.0(18)$ & 0.581 & $<0.001$ \\
\hline $1 \mathrm{y}$ & $43.1 \pm 10.8(54)$ & $<0.001$ & $30.8 \pm 10.1(15)$ & 0.401 & $<0.001$ \\
\hline \multicolumn{6}{|l|}{ PROMIS-PF } \\
\hline Preoperative & $36.4 \pm 4.9(92)$ & - & $32.6 \pm 5.3(29)$ & - & 0.001 \\
\hline $6 \mathrm{wk}$ & $38.2 \pm 6.9(77)$ & 0.017 & $33.7 \pm 5.5(21)$ & 0.444 & 0.004 \\
\hline $12 \mathrm{wk}$ & $42.2 \pm 6.4(62)$ & $<0.001$ & $37.2 \pm 6.3(18)$ & 0.043 & 0.005 \\
\hline $6 \mathrm{mo}$ & $45.3 \pm 6.7(63)$ & $<0.001$ & $39.2 \pm 7.3(16)$ & $<0.001$ & 0.003 \\
\hline $1 \mathrm{y}$ & $47.2 \pm 8.2(57)$ & $<0.001$ & $39.0 \pm 8.5(12)$ & 0.022 & 0.004 \\
\hline
\end{tabular}

Abbreviations: ODI, Oswestry Disability Index; PROMIS-PF, Patient-Reported Outcome Measurement Information System physical function; SF-12, 12-Item Short Form Physical Component Summary; VAS, visual analog scale; WC, workers' compensation. Boldface indicates statistical significance.

${ }^{\text {a }} P$ value was calculated using paired $t$ test.

${ }^{\mathrm{b}} P$ values calculated using Mann-Whitney $U$ test.

Accounting for both duration of preoperative symptoms and time from initial clinical appointment to date of surgery still demonstrated WC status as a significant predictor of mean ODI scores at all timepoints (Table 5).

\section{SF-12 PCS and PROMIS-PF}

Non-WC patients significantly improved in SF-12 PCS from the baseline values at the 12-week through 1 -year timepoint (all $P<0.01$ ). PROMIS-PF also significantly improved through 1-year follow-up (all $P<0.01)$. WC patients did not demonstrate significant improvements from baseline at any postoperative timepoint for SF-12 PCS (all $P>0.05$ ). However, PROMIS-PF demonstrated significant improvements from baseline values at 12 weeks, 6 months, and 1 year (all $P<0.05$ ). Direct comparison of SF-12 PCS and PROMIS-PF values between groups demonstrated significantly worse values for WC patients at all timepoints (all $P<0.01$ ). A summary of results can be found in Table 4. Accounting for both duration of preoperative symptoms and time from initial clinical appointment to date of surgery still demonstrated WC status as a significant predictor of mean physical function scores (SF-12 PCS and PROMIS-PF) at all timepoints (Table 5).

\section{Achievement of MCID}

A higher proportion of non-WC patients, as compared to WC patients, achieved an MCID by the 1-year timepoint $(85.9 \%$ vs $68.9 \%)$ for VAS back, ODI $(75.0 \%$ vs $43.3 \%$ ), SF-12 PCS (73.9\% vs 48.3\%), and PROMIS-PF (59.8\% vs $37.9 \%)$. Regression analysis revealed that WC status had a significant impact on achieving an MCID for VAS back at the 12 week timepoint $(P=$ $0.009)$ and overall $(P=0.040)$, whereas VAS leg was associated with MCID achievement only at the 12 week timepoint $(P=0.021)$. ODI demonstrated a relationship with MCID achievement only at 12 weeks $(P=0.013)$, 6 months $(P=0.024)$, and 1 year $(P=0.001)$. WC status also demonstrated a significant association with MCID achievement for SF-12 PCS at 6 months $(P<0.001)$ and for both SF-12 PCS $(P=0.010)$ and PROMIS-PF $(P=$ $0.039)$ for overall achievement. A summary of MCID achievement rates can be found in Table 6 . 
Table 5. Effect of duration of symptoms and time to surgery on outcomes.

\begin{tabular}{|c|c|c|c|c|c|}
\hline PROM & Coeff & $95 \% \mathrm{CI}$ & $P$ Value $^{\mathrm{a}}$ & $P$ Value $^{\mathrm{b}}$ & $P$ Value $^{\mathrm{c}}$ \\
\hline \multicolumn{6}{|l|}{ VAS back } \\
\hline Preoperative & 0.7 & -0.4 to 1.8 & 0.196 & 0.090 & 0.163 \\
\hline 6 wk & 1.8 & $0.7-2.9$ & 0.002 & 0.006 & 0.003 \\
\hline $12 \mathrm{wk}$ & 2.7 & $1.7-3.8$ & $<0.001$ & $<0.001$ & $<0.001$ \\
\hline $6 \mathrm{mo}$ & 2.8 & $1.7-3.9$ & $<0.001$ & $<0.001$ & $<0.001$ \\
\hline $1 \mathrm{y}$ & 2.5 & $0.9-4.1$ & 0.002 & 0.054 & 0.005 \\
\hline \multicolumn{6}{|l|}{ VAS leg } \\
\hline Preoperative & -0.5 & -1.7 to 0.8 & 0.480 & 0.548 & 0.539 \\
\hline $6 \mathrm{wk}$ & 1.5 & $0.3-2.7$ & 0.012 & 0.032 & 0.041 \\
\hline $12 \mathrm{wk}$ & 1.7 & $0.5-2.9$ & 0.005 & 0.005 & 0.002 \\
\hline $6 \mathrm{mo}$ & 1.8 & $0.6-2.9$ & 0.003 & 0.001 & 0.006 \\
\hline $1 \mathrm{y}$ & 2.1 & $0.3-4.0$ & 0.021 & 0.032 & 0.145 \\
\hline \multicolumn{6}{|l|}{ ODI } \\
\hline Preoperative & 9.4 & $3.2-15.7$ & 0.003 & 0.001 & 0.002 \\
\hline $6 \mathrm{wk}$ & 18.4 & $10.3-26.5$ & $<0.001$ & $<0.001$ & $<0.001$ \\
\hline $12 \mathrm{wk}$ & 21.1 & $13.9-28.4$ & $<0.001$ & $<0.001$ & $<0.001$ \\
\hline $6 \mathrm{mo}$ & 23.4 & $16.5-30.3$ & $<0.001$ & $<0.001$ & $<0.001$ \\
\hline $1 \mathrm{y}$ & 14.6 & $2.5-26.7$ & 0.019 & 0.009 & 0.018 \\
\hline \multicolumn{6}{|l|}{ SF-12 PCS } \\
\hline Preoperative & -5.6 & -9.0 to -2.2 & 0.002 & $<0.001$ & 0.002 \\
\hline $6 \mathrm{wk}$ & -6.7 & -10.9 to -2.7 & 0.001 & 0.002 & 0.001 \\
\hline $12 \mathrm{wk}$ & -9.8 & -14.3 to -5.2 & $<0.001$ & $<0.001$ & $<0.001$ \\
\hline $6 \mathrm{mo}$ & -14.7 & -20.0 to 9.3 & $<0.001$ & $<0.001$ & $<0.001$ \\
\hline $1 \mathrm{y}$ & -12.2 & -18.3 to -6.0 & $<0.001$ & 0.001 & 0.001 \\
\hline \multicolumn{6}{|l|}{ PROMIS-PF } \\
\hline Preoperative & -4.0 & -6.3 to -1.6 & 0.001 & 0.002 & 0.001 \\
\hline $6 \mathrm{wk}$ & -4.5 & -7.7 to -1.2 & 0.007 & 0.009 & 0.010 \\
\hline $12 \mathrm{wk}$ & -5.0 & -8.5 to -1.6 & 0.005 & 0.012 & 0.010 \\
\hline $6 \mathrm{mo}$ & -6.1 & -9.9 to -2.2 & 0.002 & 0.001 & 0.004 \\
\hline $1 \mathrm{y}$ & -8.2 & -13.4 to -2.9 & 0.003 & 0.011 & 0.009 \\
\hline
\end{tabular}

Abbreviations: ODI, Oswestry Disability Index; PROM, Patient-Reported Outcome Measures; PROMIS-PF, Patient-Reported Outcome Measurement Information System physical function; SF-12 PCS, 12-Item Short Form Physical Component Summary; VAS, visual analog scale; WC, workers' compensation.

Boldface indicates statistical significance.

${ }^{\text {a }} P$ value was calculated using simple linear regression to determine effect of workers' compensation status and preoperative duration of symptoms.

${ }^{\mathrm{b}} P$ value was calculated using multiple linear regression to determine effect of workers' compensation while accounting for duration of preoperative symptoms

${ }^{\mathrm{c}} P$ values calculated using multiple linear regression to determine effect of workers' compensation status while accounting for time to surgery.

Table 6. Impact of WC on patient-reported outcome measures.

\begin{tabular}{|c|c|c|c|c|c|}
\hline Outcome Measure & Preop-6 wk & Preop-12 wk & Preop-6 mo & Preop-1 y & Overall \\
\hline \multicolumn{6}{|l|}{ VAS back } \\
\hline Non-WC & $63.9 \%(53)$ & $77.6 \%(59)$ & $72.0 \%(54)$ & $77.1 \%(37)$ & $85.9 \%(79)$ \\
\hline WC & $52.0 \%$ & $50.0 \%(12)$ & $60.0 \%(15)$ & $61.5 \%(8)$ & $68.9 \%(20)$ \\
\hline$P$ value $^{\mathrm{a}}$ & 0.286 & 0.009 & 0.261 & 0.258 & 0.040 \\
\hline \multicolumn{6}{|l|}{ VAS leg } \\
\hline Non-WC & $61.5 \%(51)$ & $71.4 \%(57)$ & $68.0 \%(52)$ & $58.3 \%(28)$ & $78.3 \%(72)$ \\
\hline WC & $40.0 \%(10)$ & $45.8 \%(11)$ & $48.0 \%(12)$ & $61.5 \%(8)$ & $62.0 \%(18)$ \\
\hline$P$ value $^{\mathrm{a}}$ & 0.058 & 0.021 & 0.073 & 0.835 & 0.082 \\
\hline \multicolumn{6}{|l|}{ ODI } \\
\hline Non-WC & $40.5 \%$ & $44.9 \%(35)$ & $61.8 \%(47)$ & $66.7 \%(32)$ & $75.0 \%(69)$ \\
\hline WC & $24.0 \%(6)$ & $16.7 \%(4)$ & $36.0 \%(9)$ & $46.1 \%(6)$ & $43.3 \%(12)$ \\
\hline$P$ value $^{\mathrm{a}}$ & 0.133 & 0.013 & 0.024 & 0.176 & 0.001 \\
\hline \multicolumn{6}{|l|}{ SF-12 PCS } \\
\hline Non-WC & $33.8 \%(26)$ & $52.9 \%(36)$ & $69.3 \%(43)$ & $75.9 \%(41)$ & $73.9 \%(68)$ \\
\hline WC & $18.1 \%(4)$ & $30.4 \%(7)$ & $22.2 \%(4)$ & $53.3 \%(8)$ & $48.3 \%(14)$ \\
\hline$P$ value ${ }^{\mathrm{a}}$ & 0.161 & 0.062 & $<0.001$ & 0.088 & 0.010 \\
\hline \multicolumn{6}{|l|}{ PROMIS-PF } \\
\hline Non-WC & $15.6 \%(12)$ & $37.1 \%(23)$ & $50.8 \%(32)$ & $57.9 \%(33)$ & $59.8 \%(55)$ \\
\hline WC & $9.5 \%(2)$ & $22.2 \%$ & $43.7 \%(7)$ & $25.0 \%(3)$ & $37.9 \%$ \\
\hline$P$ value $^{\mathrm{a}}$ & 0.482 & 0.227 & 0.615 & 0.034 & 0.039 \\
\hline
\end{tabular}

Abbreviations: MCID, minimum clinically important difference; PROMIS-PF, Patient-Reported Outcome Measurement Information System physical function; SF-12 PCS, 12Item Short Form Physical Component Summary; VAS, visual analog scale; WC, workers' compensation.

The following MCID values derived from Copay et al; VAS back = 1.2, VAS leg = 1.6, ODI = 12.8; or Parker et al; SF-12 = 4.0; PROMIS MCID values derived from Hung et al PROMIS-PF $=8.0$.

Data presented as \% (n). Boldface indicates statistical significance.

${ }^{\mathrm{a}} P$ value was calculated for each category using logistic regression. 


\section{DISCUSSION}

Lower back pain continues to be a leading cause of disability in the working population. Given that WC patients will continue to represent a significant proportion of spine patients, surgeons continue to refine treatments that will effectively and efficiently return patients to work. ${ }^{5}$ While past studies have suggested that WC is associated with worse postoperative outcomes, few studies have commented on its effect on achievement of an MCID. This study aimed to expand the assessment of WC on postoperative outcomes to physical function and achievement of MCID and demonstrated that WC patients report worse pain, disability, and physical function across multiple timepoints.

The current study observed a disproportionate number of WC recipients experienced worse postoperative pain and a significantly lower rate of MCID achievement. These results aligned well with previous studies that reported WC as a risk factor for both increased postoperative pain ${ }^{15}$ and lower likelihood of achieving an MCID for VAS back compared to those with other forms of insurance ( $51.85 \%$ vs $87.39 \%) .{ }^{20}$ The effects of WC status on VAS scores may also extend beyond the 1-year timepoint, as previous studies have reported worse postoperative pain at 2 years among the WC cohort. ${ }^{17}$ Interestingly, while our study affirms that WC status negatively impacted postoperative VAS scores, preoperative values demonstrated similar levels as non-WC patients. Collectively, these results may imply that WC patients may endure a longer road to recovery of pain and may require a more extensive follow-up plan. Additionally, the persistence of lower back pain may also increase the odds (OR: 1.46) of continued opioid use. ${ }^{25}$

In conjunction with pain and depressive symptoms, disability is more commonly reported by WC patients than non-WC patients. ${ }^{26}$ Our study was able to corroborate this observation as the WC group demonstrated nonsignificant improvements from baseline values as well as worse disability scores compared to the non-WC group at all timepoints. Although this may be attributed to a smaller group size $(n=29)$ as compared to the non-WC group $(n=92)$, this may also reflect persistent disability of this population. In line with our results, other investigators reported that WC patients experienced significantly worse back disability (ODI) up to 2 years (5.5 vs 15.2) compared to non-WC patients. ${ }^{14}$ Interestingly, Gum et al reported no differences in MCID achievement for ODI between WC cohorts while the current study demonstrated a significantly lower proportion of patients achieved an MCID at 6 months. ${ }^{14}$ One possible explanation for the discrepancy is a difference in demographics, in particular age. Similar to our study, Gum et al performed a propensity match to avoid confounding effects of demographics but reported a mean age approximately 10 years younger, which has been reported as a predictor for MCID achievement. ${ }^{14}$ Alternatively, this difference may simply be an effect of diminished improvements in pain, which has shown strong correlations with disability. ${ }^{27}$ Considering these results, WC patients undergoing surgical treatment for symptomatic lumbar spine pathologies may need to be counseled regarding the lengthened course of postoperative improvement in disability as well as pain.

In addition to WC status acting as a potential risk factor for worse postoperative outcomes, the impact of duration of symptoms or prolongation of date of surgery were also analyzed in the current study. Majority of patients were able to undergo surgical treatment within 6 months from their initial clinical evaluation regardless of their WC status. However, there was a significantly higher proportion of patients in the WC group that had a duration of symptom in the 6-month to 1-year range and a higher proportion of non-WC patients with a duration of symptoms $>1$ year. Yet, regression analysis demonstrated that both the length of time patients endure symptoms and the length of time from initial clinical visit to surgery were not significant contributors to the variation in mean pain, disability, and physical function between groups. Prior studies have also examined the impact of duration of symptoms on lumbar spine populations and reported no significant difference in improvement of pain and disability or sagittal alignment. ${ }^{28}$ More specific to the TLIF population, Yoo et al also demonstrated that while patients with a duration of symptoms $<12$ months, demonstrated significantly worse preoperative VAS leg and ODI, ultimately all patients achieved a similar level of improvement by final follow-up. ${ }^{29}$ These results coupled with the current study suggest that WC patients may have an inherently longer recovery course and may not necessarily be at risk for even worse outcomes if they endure preoperative symptoms for a longer period of time.

In line with poorer pain and disability improvement, assessment of physical function among compensated patients was worse compared to noncompensated patients, a result that was echoed by 
MCID achievement rates. Comparisons to current literature are limited; however, Hee et al reported that receiving $\mathrm{WC}$ is a significant predictor of lower SF-36 scores for general health $(P<0.0001)$ and physical function $(P<0.0001)$, as well as in mental and social components. ${ }^{30}$ An added strength of our study is the use of PROMIS-PF in addition to "legacy PROMs" (VAS, ODI, and SF-12). Similar to SF-12 PCS, PROMIS-PF did not improve to the same degree as non-WC patients through the 1-year timepoint. This result aligned well with the observed lower rates of MCID achievement for both SF-12 PCS and PROMIS-PF by the 1-year mark. Similar to SF-12 PCS, few studies, if any, have evaluated the impact of WC on PROMIS-PF. While the association with worse postoperative physical function among WC patients may not be inherently clear, this population tends to view/rate their health in a less favorable light, ${ }^{19}$ and it has been suggested that they tend to be more severely disabled and less active overall. ${ }^{31}$ These reasons may cause a lower compliance with rehabilitation, and ultimately, their recovery and could cause patients to be less incentivized to elicit a change in their physical abilities.

While WC patients may be at increased risk for poorer postoperative outcomes compared to non-WC patients, the current study maintains that patients were still able to achieve an appreciable change by 1-year follow-up. This ability for WC patients to significantly improve may be, in part, attributed to patient selection and strict decision making by the senior author. Appropriate choice of patients may be a significant factor to successful outcomes as previous studies have highlighted that different selections between neurosurgery and orthopedic spine surgeons resulted in different rates of reoperation. ${ }^{32}$ However, this aspect is beyond the scope of the current study, but future studies that outline specific selection criteria for surgery among the WC population may further elucidate its role in potentiating positive postoperative outcomes.

\section{Limitations}

This study has several limitations that should be considered. First, patients received treatment at a single institution by a sole spine surgeon, which limits the generalizability of our results. Second, a propensity score match was performed, which limits the number of patients included in this study. This not only impacts the power of our study but may also cause selection bias in our cohort. Third, outcomes were assessed using PROMs, which carry the potential for recall and responder bias. Lastly, the severity of injury among WC patients may not be uniform, which may impact baseline levels and subsequent calculations of postoperative improvement.

\section{CONCLUSION}

This propensity score-matched study demonstrated that WC patients experienced similar preoperative pain but worse disability and physical function. While non-WC patients were able to achieve significant improvements in all outcomes by the 1-year timepoint, WC patients demonstrated variable improvement in pain, disability, and physical function. Direct comparisons of postoperative outcome values between groups demonstrated significantly worse scores for WC patients through 1 year. Additionally, WC patients do not enjoy a similar rate of MCID achievement by the 1-year timepoint as their control counterparts. These results collectively suggest that WC patients may be at increased risk for worse postoperative outcomes and may endure a longer postoperative recovery as compared to non-WC patients following MIS TLIF.

\section{REFERENCES}

1. Driscoll T, Jacklyn G, Orchard J, et al. The global burden of occupationally related low back pain: estimates from the Global Burden of Disease 2010 study. Ann Rheum Dis. 2014;73(6):975-981. doi:10.1136/annrheumdis-2013-204631

2. Leigh JP. Economic burden of occupational injury and illness in the United States. Milbank Q. 2011;89(4):728-772. doi:10.1111/ j.1468-0009.2011.00648.x

3. Guo HR, Tanaka S, Halperin WE, Cameron LL. Back pain prevalence in US industry and estimates of lost workdays. Am J Public Health. 1999;89(7):1029-1035. doi:10.2105/ajph.89.7.1029

4. Keeney BJ, Fulton-Kehoe D, Turner JA, Wickizer TM, Chan KCG, Franklin GM. Early predictors of lumbar spine surgery after occupational back injury: results from a prospective study of workers in Washington State. Spine (Phila Pa 1976). 2013;38(11):953-964. doi:10.1097/BRS.0b013e3182814ed5

5. Harris I, Mulford J, Solomon M, van Gelder JM, Young J. Association between compensation status and outcome after surgery: a meta-analysis. JAMA. 2005;293(13):1644-1652. doi:10.1001/ jama.293.13.1644

6. Nguyen TH, Randolph DC, Talmage J, Succop P, Travis R. Long-term outcomes of lumbar fusion among workers' compensation subjects: a historical cohort study. Spine (Phila Pa 1976). 2011;36(4):320-331. doi:10.1097/BRS.0b013e3181ccc220

7. Turner JA, Franklin G, Turk DC. Predictors of chronic disability in injured workers: a systematic literature synthesis. Am J Ind Med. 2000;38(6):707-722. doi:10.1002/1097-0274(200012).

8. Atlas SJ, Tosteson TD, Hanscom B, et al. What is different about worker's compensation patients? Spine. 2007;32(18):2019-2026. doi:10.1097/BRS.0b013e318133d69b 
9. Krause N, Frank JW, Dasinger LK, Sullivan TJ, Sinclair SJ. Determinants of duration of disability and return-to-work after work-related injury and illness: challenges for future research. Am J Ind Med. 2001;40(4):464-484. doi:10.1002/ajim.1116

10. Latza U, Kohlmann T, Deck R, Raspe H. Influence of occupational factors on the relation between socioeconomic status and selfreported back pain in a population-based sample of German adults with back pain. Spine (Phila Pa 1976). 2000;25(11):1390-1397. doi:10.1097/00007632-200006010-00011

11. Daniels AH, Kuris EO, Kleinhenz DT, Palumbo MA. Spine surgery outcomes in workers' compensation patients. J Am Acad Orthop Surg. 2017;25(10):e225-e234. doi:10.5435/JAAOS-D-1600895

12. Shaw WS, Pransky G, Patterson W, Winters T. Early disability risk factors for low back pain assessed at outpatient occupational health clinics. Spine (Phila Pa 1976). 2005;30(5):572-580. doi:10.1097/01.brs.0000154628.37515.ef

13. Cuneo JG, DeBerard MS, Wheeler AJ. Lumbar fusion in Utah workers' compensation patients: changing outcomes across a decade. Spine (Phila Pa 1976). 2017;42(9):692-699. doi:10.1097/ BRS.0000000000001964

14. Gum JL, Glassman SD, Carreon LY. Is type of compensation a predictor of outcome after lumbar fusion? Spine (Phila Pa 1976). 2013;38(5):443-448. doi:10.1097/BRS.0b013e318278ebe8

15. Jenkins NW, Parrish JM, Mayo BC, et al. The identification of risk factors for increased postoperative pain following minimally invasive transforaminal lumbar interbody fusion. Eur Spine J. 2020;29(6):1304-1310. doi:10.1007/s00586-020-06344-4

16. Ahn J, Bohl DD, Tabaraee E, Aboushaala K, Elboghdady IM, Singh K. Preoperative narcotic utilization: accuracy of patient self-reporting and its association with postoperative narcotic consumption. J Neurosurg Spine. 2016;24(1):206-214. doi:10.3171/20 15.3.SPINE141300

17. Anderson JT, Haas AR, Percy R, Woods ST, Ahn UM, Ahn NU. Chronic opioid therapy after lumbar fusion surgery for degenerative disc disease in a workers' compensation setting. Spine (Phila Pa 1976). 2015;40(22):1775-1784. doi:10.1097/ BRS.0000000000001054

18. Franklin GM, Stover BD, Turner JA, Fulton-Kehoe D, Wickizer TM, Disability Risk Identification Study Cohort. Early opioid prescription and subsequent disability among workers with back injuries: the Disability Risk Identification Study Cohort. Spine (Phila Pa 1976). 2008;33(2):199-204. doi:10.1097/ BRS.0b013e318160455c

19. Compton J, Glass N, Fowler T. The effect of workers' compensation status on the patient experience. JB JS Open Access. 2019;4(2):e0003. doi:10.2106/JBJS.OA.19.00003

20. Hijji FY, Narain AS, Bohl DD, et al. Risk factors associated with failure to reach minimal clinically important difference in patient-reported outcomes following minimally invasive transforaminal lumbar interbody fusion for spondylolisthesis. Clin Spine Surg. 2018;31(1):E92-E97. doi:10.1097/ BSD.0000000000000543

21. Djurasovic M, Bratcher KR, Glassman SD, Dimar JR, Carreon LY. The effect of obesity on clinical outcomes after lumbar fusion. Spine (Phila Pa 1976). 2008;33(16):1789-1792. doi:10.1097/BRS.0b013e31817b8f6f

22. Copay AG, Glassman SD, Subach BR, Berven S, Schuler TC, Carreon LY. Minimum clinically important difference in lumbar spine surgery patients: a choice of methods using the Oswestry Disability Index, Medical Outcomes Study questionnaire Short Form
36, and pain scales. Spine J. 2008;8(6):968-974. doi:10.1016/j. spinee.2007.11.006

23. Parker SL, Mendenhall SK, Shau DN, et al. Minimum clinically important difference in pain, disability, and quality of life after neural decompression and fusion for same-level recurrent lumbar stenosis: understanding clinical versus statistical significance. J Neurosurg Spine. 2012;16(5):471-478. doi:10.3171/ 2012.1.SPINE11842

24. Hung M, Saltzman CL, Kendall R, et al. What are the MCIDs for PROMIS, NDI, and ODI instruments among patients with spinal conditions? Clin Orthop Relat Res. 2018;476(10):2027-2036. doi:10.1097/CORR.0000000000000419

25. O'Hara NN, Pollak AN, Welsh CJ, et al. Factors associated with persistent opioid use among injured workers' compensation claimants. JAMA Netw Open. 2018;1(6):e184050. doi:10.1001/ jamanetworkopen.2018.4050

26. Rainville J, Sobel JB, Hartigan C, Wright A. The effect of compensation involvement on the reporting of pain and disability by patients referred for rehabilitation of chronic low back pain. Spine (Phila Pa 1976). 1997;22(17):2016-2024. doi:10.1097/00007632199709010-00016

27. MacCormick AP, Sharma H. Does the severity of pain correlate with severity of functional disability? Factors influencing "patient reported outcome measures" in spinal patients. SICOT J. 2018;4:43. doi:10.1051/sicotj/2018029

28. Sayari AJ, Harada GK, Basques BA, et al. Duration of symptoms does not affect clinical outcome after lumbar arthrodesis. Clinical Spine Surgery. 2021;34(2):E72-E79. doi:10.1097/ BSD.0000000000001045

29. Yoo JS, Patel DS, Hrynewycz NM, Brundage TS, Mogilevsky FA, Singh K. The effect of preoperative symptom duration on postoperative outcomes after minimally invasive transforaminal lumbar interbody fusion. Clin Spine Surg. 2020;33(6):E263-E268. doi:10.1097/BSD.0000000000000881

30. Hee HT, Whitecloud TS, Myers L, Gaynor J, Roesch W, Ricciardi JE. SF-36 health status of workers compensation cases with spinal disorders. Spine J. 2001;1(3):176-182. doi:10.1016/ s1529-9430(01)00080-8

31. Turk DC, Okifuji A. Perception of traumatic onset, compensation status, and physical findings: impact on pain severity, emotional distress, and disability in chronic pain patients. $J$ Behav Med. 1996;19(5):435-453. doi:10.1007/BF01857677

32. Bronheim RS, Kim JS, Di Capua J, et al. High-risk subgroup membership is a predictor of 30-day morbidity following anterior lumbar fusion. Global Spine J. 2017;7(8):762-769. doi:10.1177/2192568217696691

Funding: The author(s) received no financial support for the research, authorship, and/or publication of this article.

\section{Declaration of Conflicting Interests: Kern}

Singh discloses that he has received grants or contracts from the Cervical Spine Research Society; royalties or licenses from RTI Surgical, Zimmer Biomet, Stryker, Lippincott Williams \& Wilkins, Theime, Jaypee Publishing, and Slack Publishing; consulting fees from K2M and Zimmer Biomet; patents planned, issued, or pending with TDi LLC; and leadership or fiduciary role 
on Vitals 5 LLC, TDi LLC, Minimally Invasive Spine Study Group, Contemporary Spine Surgery, Orthopedics Today, and Vertebral Columns. The remaining authors have no disclosures.

IRB Approval: ORA \#14051301

Disclosures: No benefits in any form have been or will be received from any commercial party related directly or indirectly to the subject of this manuscript.
Corresponding Author: Kern Singh, Department of Orthopaedic Surgery, Rush University Medical Center, 1611 W. Harrison St, Suite \#300, Chicago, IL 60612, USA; kern.singh@rushortho.com

Published 15 February 2022

This manuscript is generously published free of charge by ISASS, the International Society for the Advancement of Spine Surgery. Copyright (C) 2022 ISASS. To see more or order reprints or permissions, see http:// ijssurgery.com. 